Article

\title{
Biodistribution, Stability, and Blood Distribution of the Cell Penetrating Peptide Maurocalcine in Mice
}

\author{
Pascale Perret 1,2, , Mitra Ahmadi 1,2, Laurent Riou ${ }^{1,2}$, Sandrine Bacot 1,2, Julien Pecher ${ }^{3}$, \\ Cathy Poillot ${ }^{1,4}$, Alexis Broisat ${ }^{1,2}$, Catherine Ghezzi ${ }^{1,2,+}$ and Michel De Waard 1,3,4, + \\ Received: 27 August 2015 ; Accepted: 22 October 2015 ; Published: 19 November 2015 \\ Academic Editor: Jagdish Singh \\ 1 Grenoble Alpes University, 38041 Saint-Martin-d'Hères, France; mitra.ahmadi@ujf-grenoble.fr (M.A.); \\ laurent.riou@ujf-grenoble.fr (L.R.); sandrine.bacot@ujf-grenoble.fr (S.B.); cathy.poillot@gmail.com (C.P.); \\ alexis.broisat@inserm.fr (A.B.); catherine.ghezzi@ujf-grenoble.fr (C.G.); \\ dewaardm@ujf-grenoble.fr (M.D.W.) \\ 2 Radiopharmaceutiques Biocliniques, INSERM, UMR S1039, 38700 La Tronche, France \\ 3 Smartox Biotechnologies, Bâtiment Nanobio, 570 rue de la Chimie, 38400 Saint Martin d'Hères, France; \\ julien.pecher@gmail.com \\ 4 Science and Therapeutics, LabEx Ion Channels, Grenoble Institute of Neuroscience, INSERM, U836, \\ 38700 La Tronche, France \\ * Correspondence: pascale.perret@ujf-grenoble.fr; Tel.: +33-476-637-102 \\ + These authors contributed equally to this work.
}

\begin{abstract}
Maurocalcine (MCa) is the first natural cell penetrating peptide to be discovered in animal venom. In addition to the fact that it represents a potent vector for the cell penetration of structurally diverse therapeutic compounds, $\mathrm{MCa}$ also displays several distinguishing features that make it a potential peptide of choice for clinical and biotechnological applications. The aim of the present study was to gain new information about the properties of MCa in vivo in order to delineate the future potential applications of this vector. For this purpose, two analogues of this peptide with (Tyr-MCa) and without (Lin-Tyr-MCa) disulfide bridges were synthesized, radiolabeled with ${ }^{125} \mathrm{I}$, and their in vitro stabilities were first evaluated in mouse blood. The results indicated that ${ }^{125} \mathrm{I}$-Tyr-MCa was stable in vitro and that the disulfide bridges conferred a competitive advantage for the stability of peptide. Following in vivo injection in mice, ${ }^{125} \mathrm{I}-\mathrm{Tyr}-\mathrm{MC}$ a targeted peripheral organs with interesting quantitative differences and the main route of peptide elimination was renal.
\end{abstract}

Keywords: maurocalcine; cell-penetrating peptide; in vivo biodistribution; drug delivery; blood stability

\section{Introduction}

Maurocalcine (MCa) has been extracted from the venom of the Scorpio maurus palmatus and identified as a 33-mer peptide [1]. Evidence that the coupling of a biotinylated derivative of MCa to streptavidin tagged with a fluorescent dye leads to fluorescence accumulation in a variety of cell types indicated that MCa could act as a peptide vector for the cell entrance of a cargo [2]. Additional studies indicated that glycoaminoglycans and negatively charged phospholipids represent membrane receptors of MCa [3]. At the structural level, MCa folds according to an inhibitor cysteine knot motif and contains three well-defined beta-strands [1]. The secondary structures are constrained by three disulfide bridges with a pattern of connectivity forming the unusual knot. A specificity of MCa is that it is heavily charged owing to the presence of basic amino acid residues. This property, along with the fact that MCa has the ability to induce cell penetration of a variety of cargo [4-8], led to the conclusion that MCa was the first identified toxin member of the large structurally-unrelated family 
of cell penetrating peptides (CPP). CPP are becoming increasingly popular as vectors for the cell entry of cargo that would otherwise not enter cells. As such, MCa demonstrated excellent vector properties for quantum dots, peptides, or drugs, and promising applications are envisioned in oncology [4,9-12]. Considering the potential of the natural form of MCa as a vector, we quantitatively investigated its cell penetration properties in a recent study. This was done by grafting an additional Tyr residue at the N-terminus of the peptide followed by appropriate iodination with ${ }^{125} \mathrm{I}$ to provide first Tyr-MCa and next ${ }^{125} \mathrm{I}-\mathrm{Tyr}-\mathrm{MCa}$. The results indicated that dose-dependent accumulation of radioiodinated Tyr-MCa was observed in the nucleus and cytoplasm of rat F98 glioma cells with $>24 \mathrm{~h}$ cellular retention [13]. While MCa is recognized as a competitive CPP due to its low concentration efficacy and ability to reach the cytoplasm, additional efforts were made to obtain MCa analogues deprived of undesirable pharmacological effects yet with preserved cell penetration properties. In this regard, the structural stringency observed for MCa binding to RyR1 is much higher than that observed for MCa cellular penetration. Hence, all strategies tested so far provided cell penetrating competent analogues that lacked RyR1 binding $[7,8,14]$. In essence, venomous toxins are delivered in vivo and are tailored to survive enough time within the blood stream of animal preys until the pharmacological potential of these molecules has been fully exploited. Two analogues of this peptide were synthesized in order to investigate the in vivo properties of MCa, namely Tyr-MCa that like the natural form of MCa contains three disulfide bridges according to the pattern of $\mathrm{Cys}^{3}-\mathrm{Cys}^{17}, \mathrm{Cys}^{10}-\mathrm{Cys}^{21}$ and $\mathrm{Cys}^{16}-\mathrm{Cys}^{32}$, and Lin-Tyr-MCa without disulfide bridges therefore lacking any three-dimensional structure [8]. The rationale underlying the synthesis of Lin-Tyr-MCa was that the synthesis of a peptide with multiple disulfide bridges might raise technical difficulties as compared to a linear peptide. The replacement of the six MCa internal cysteine residues by 2-Aminobutyric acid ( $\mathrm{Abu}$ ) residues results in a linear peptide lacking a secondary structure while retaining its CPP properties [8]. The synthesis of Tyr-MCa and Lin-Tyr-MCa as performed in the present study therefore allowed the evaluation of the role of MCa secondary structure on the in vitro and in vivo peptide stability. Specifically, each peptide contained an extra amino-terminal tyrosine residue for the purpose of radioiodination. The in vitro metabolic stability of ${ }^{125} \mathrm{I}$-labeled peptides as well as the body distribution pattern and route of elimination of ${ }^{125} \mathrm{I}$-Tyr-MCa were studied. The present study will help to delineate the in vivo potential of MCa as a CPP.

\section{Results}

\subsection{Chemical Synthesis and Radiolabeling}

MCa amino acid sequence is devoid of internal Tyr residue for peptide iodination. To facilitate the labeling of MCa analogues, we chemically synthesized the 34 amino acid Tyr-MCa and Lin-Tyr-MCa that each contains an additional Tyr residue at the N-terminus of the sequence. The Lin-Tyr-MCa contains no disulfide bridge while the Tyr-MCa folds well in spite of the extra Tyr residue and possesses the classical disulfide bridging pattern. Next, ${ }^{125} \mathrm{I}$-Tyr-MCa and ${ }^{125} \mathrm{I}$-Lin-Tyr-MCa are prepared using lactoperoxidase $/ \mathrm{H}_{2} \mathrm{O}_{2}$ as oxidative agents. RP-HPLC analysis of the radioiodinated peptides immediately following radiolabeling is shown in Figure 1. The results indicate that the radioiodination procedure yields a single major radioactive species with radiochemical purity $(\mathrm{RCP})>95 \%$. ${ }^{125} \mathrm{I}$-Tyr-MCa and ${ }^{125} \mathrm{I}$-Lin-Tyr-MCa remain stable (RCP $>95 \%$ ) at room temperature for at least $24 \mathrm{~h}$ following radiolabeling. For all subsequent experiments, ${ }^{125} \mathrm{I}$-Tyr-MCa is always used within $12 \mathrm{~h}$ following radiolabeling.

\subsection{In Vitro Stability in Mouse Blood}

The in vitro distribution pattern of radioactivity after 15, 30, 60, 90, 120 and $180 \mathrm{~min}$ of incubation of ${ }^{125} \mathrm{I}$-Tyr-MCa and ${ }^{125} \mathrm{I}$-Lin-Tyr-MCa with whole mouse blood is indicated in Table 1 . The results indicate that the fraction of ${ }^{125} \mathrm{I}-\mathrm{Ty}$ r-MCa and ${ }^{125} \mathrm{I}$-Lin-Tyr-MCa associated to blood cells remain quite stable over time at $\sim 20 \%$ for ${ }^{125} \mathrm{I}$-Tyr-MCa and $30 \%$ to $45 \%$ for ${ }^{125} \mathrm{I}$-Lin-Tyr-MCa. ${ }^{125} \mathrm{I}$-Tyr-MCa 
is mostly associated with plasma proteins $\left(\sim 60 \%-70 \%\right.$ of total) while ${ }^{125} \mathrm{I}$-Lin-Tyr-MCa binding to plasma proteins decreases from $47 \%$ to $27 \%$ at $180 \mathrm{~min}$. The protein-free plasma sample used for HPLC analysis contains $~ 10 \%$ of radioactivity for ${ }^{125} \mathrm{I}$-Tyr-MCa and increases progressively from $23 \%$ to $30 \%$ for ${ }^{125}$ I-Lin-Tyr-MCa.
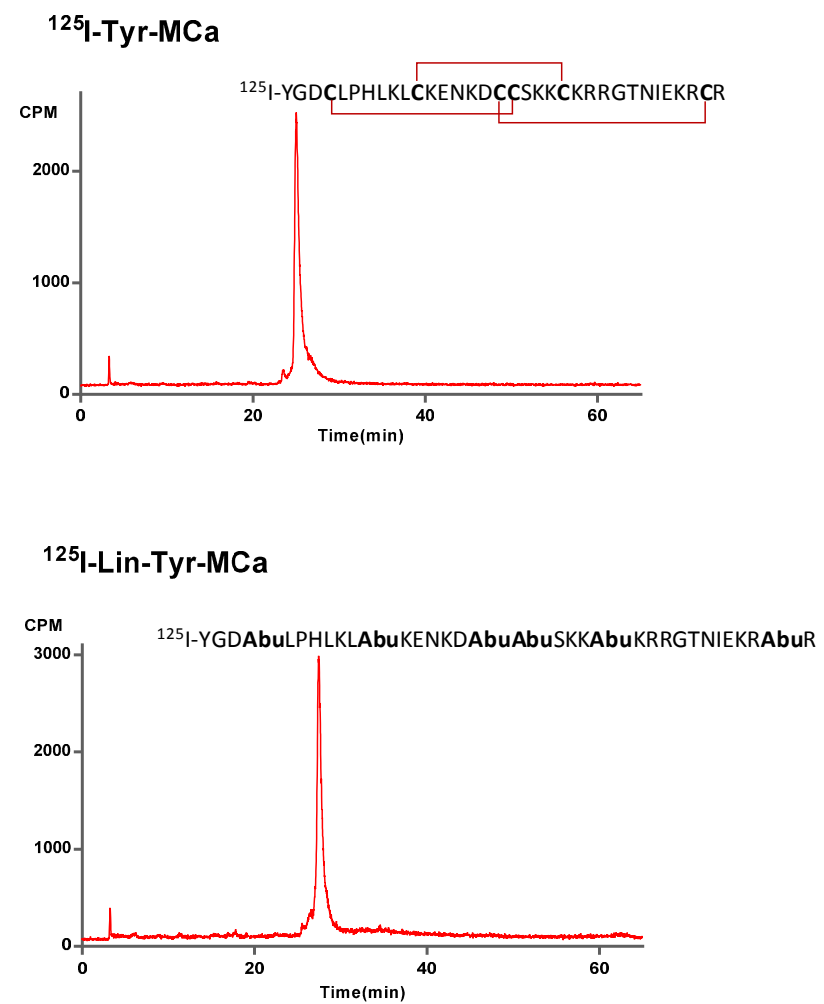

Figure 1. ${ }^{125} \mathrm{I}-\mathrm{Tyr}-\mathrm{MCa}$ and ${ }^{125} \mathrm{I}-\mathrm{Lin}-\mathrm{Tyr}-\mathrm{MCa}$ peptidic sequences and RP-HPLC profiles following radiolabeling.

Table 1. In vitro blood distribution patterns of radioactivity following ${ }^{125} \mathrm{I}$-Tyr-MCa and ${ }^{125}$ I-Lin-Tyr-MCa incubation with whole murine blood.

\begin{tabular}{|c|c|c|c|c|c|c|}
\hline Blood Distribution & $15 \mathrm{~min}$ & $30 \mathrm{~min}$ & $60 \mathrm{~min}$ & $90 \mathrm{~min}$ & $120 \mathrm{~min}$ & $180 \mathrm{~min}$ \\
\hline \multicolumn{7}{|l|}{${ }^{125}$ I-Tyr-MCa } \\
\hline Blood cells & $22 \pm 3$ & $21 \pm 3$ & $22 \pm 1$ & $19 \pm 3$ & $18 \pm 0$ & $19 \pm 2$ \\
\hline Plasma proteins & $64 \pm 3$ & $65 \pm 5$ & $64 \pm 3$ & $67 \pm 3$ & $69 \pm 2$ & $70 \pm 2$ \\
\hline $\begin{array}{l}\text { Protein-free plasma } \\
{ }^{125} \text { I-Lin-Tyr-MCa }\end{array}$ & $12 \pm 4$ & $12 \pm 4$ & $12 \pm 3$ & $12 \pm 1$ & $11 \pm 1$ & $9 \pm 2$ \\
\hline Blood cells & $30 \pm 5$ & $31 \pm 8$ & $35 \pm 3$ & $35 \pm 9$ & $37 \pm 9$ & $44 \pm 10$ \\
\hline Plasma proteins & $47 \pm 3$ & $42 \pm 3$ & $34 \pm 2$ & $32 \pm 0.4$ & $34 \pm 1$ & $27 \pm 5$ \\
\hline Protein-free plasma & $23 \pm 4$ & $23 \pm 2$ & $22 \pm 3$ & $30 \pm 10$ & $28 \pm 8$ & $28 \pm 8$ \\
\hline
\end{tabular}

Radioactive species ratios calculated from HPLC analyses of the protein-free plasma fraction of mouse blood samples following 15 to $180 \mathrm{~min}$ of incubation with the tracers are shown in Figure 2. In this figure, the 0 min time point corresponds to radioiodinated Tyr-MCa and Lin-Tyr-MCa immediately following radiolabeling and before contact with mouse blood. The iodinated metabolite of ${ }^{125} \mathrm{I}$-Tyr-MCa represents $1.3 \% \pm 0.5 \%$ of the total radioactivity at $15 \mathrm{~min}$ and increases to $6 \% \pm 2 \%$ at $180 \mathrm{~min}$, indicating that the peptide retains excellent stability. The amount of free ${ }^{125} \mathrm{I}$ is stable over $90 \mathrm{~min}$ and represents $\sim 20 \%-25 \%$ of the protein-free plasma fraction of radioactivity and then increases up to $\sim 58 \%$ at $180 \mathrm{~min}$, indicating good ${ }^{125} \mathrm{I}$-Tyr-MCa stability for $90 \mathrm{~min}$. Single-photon emission computed tomography (SPECT) imaging and biodistribution studies are performed up to 
$60 \mathrm{~min}$ following injection in order to account for the increased deiodination observed thereafter. In this setting, the $\sim 20 \%-25 \%$ of free ${ }^{125}$ I detected in the protein-free plasma fraction of radioactivity correspond to $\sim 4 \%$ of total blood activity since free ${ }^{125} \mathrm{I}$ is exclusively located in the protein-free plasma fraction as shown by results from TLC analysis (data not shown).

${ }^{125} \mathrm{I}$-Lin-Tyr-MCa is degraded as early as 15 min of incubation with appearance of $11 \% \pm 2 \%$ of a first iodinated metabolite $\left({ }^{125} \mathrm{I}\right.$-metabolite-1). A second iodinated metabolite $\left({ }^{125} \mathrm{I}\right.$-metabolite-2) appears after $15 \mathrm{~min}$ of incubation which proportion increases to $4.3 \% \pm 1 \%$ at $120 \mathrm{~min}$. Finally, a third iodinated metabolite ( ${ }^{125}$ I-metabolite-3) appears at $180 \mathrm{~min}$ while the presence of ${ }^{125}$ I-metabolite-1 and ${ }^{125} \mathrm{I}$-metabolite- 2 is concomitantly observed. The amount of free ${ }^{125} \mathrm{I}$ is stable $(\sim 30 \%)$ and ${ }^{125} \mathrm{I}$-Lin-Tyr-MCa decreases to $31.3 \% \pm 6 \%$ after $180 \mathrm{~min}$ of incubation.

Radioiodinated metabolites of ${ }^{125} \mathrm{I}$-Lin-Tyr-MCa evidenced by in vitro experiments can interfere in vivo biodistribution and imaging studies. Accordingly, all subsequent in vivo tracer evaluations are performed using ${ }^{125} \mathrm{I}$-Tyr-MCa only.
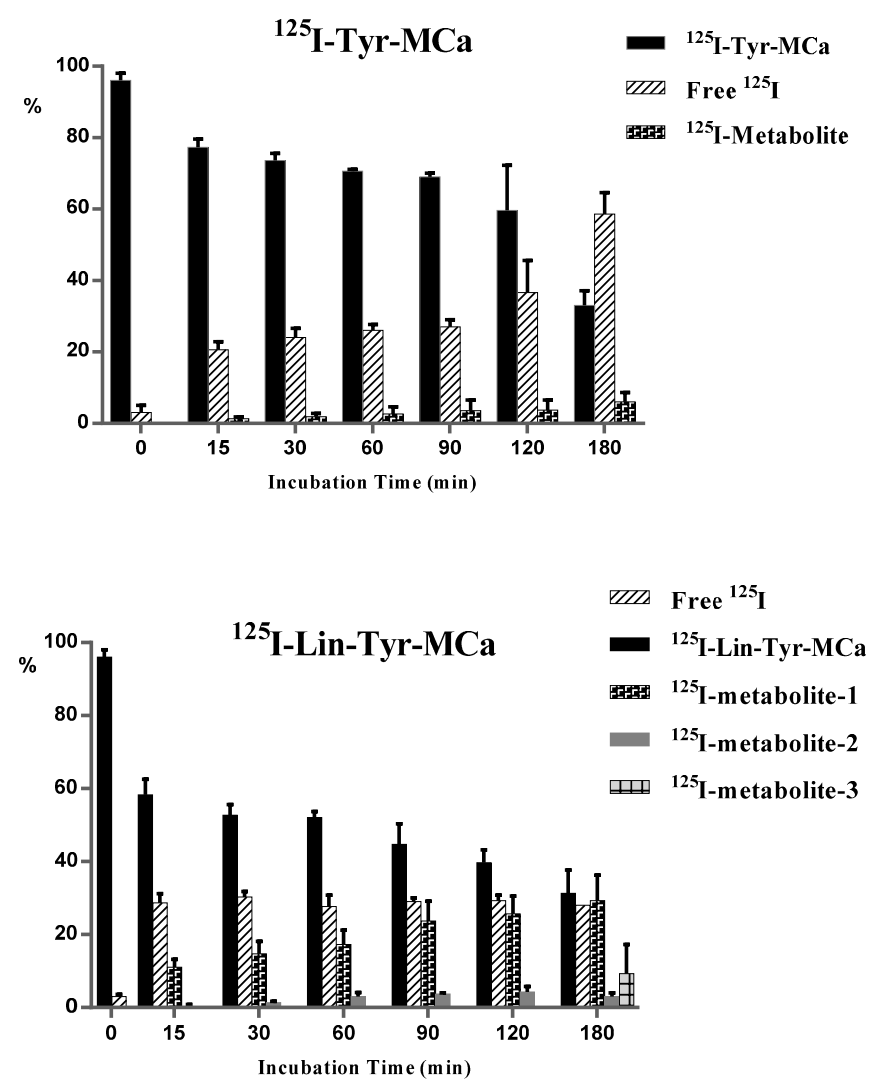

Figure 2. Evaluation of ${ }^{125} \mathrm{I}-\mathrm{Ty}$ r-MCa and ${ }^{125} \mathrm{I}$-Lin-Tyr-MCa stabilities following 15 to $180 \mathrm{~min}$ of incubation with whole murine blood. The $0 \mathrm{~min}$ time point refers to ratios observed immediately following radioiodination.

\subsection{In Vivo Tracer Stability}

In vivo blood distribution pattern of radioactivity following ${ }^{125} \mathrm{I}$-Tyr-MCa intravenous injection is indicated in Table 2. As observed in vitro, the radioactivity is mostly associated with plasma proteins, although to a slightly lower level. The remaining activity is equally distributed between blood cells and the protein-free plasma fraction. HPLC analysis of radioactive species in the protein-free plasma fraction of mouse blood at 15 and $30 \mathrm{~min}$ post-injection in mice pretreated by the $\mathrm{NaI}$ symporter inhibitor potassium perchlorate indicates the presence of free ${ }^{125} \mathrm{I}$ and ${ }^{125} \mathrm{I}$-Tyr-MCa. Free ${ }^{125} \mathrm{I}$ represents $\sim 62 \%$ of the total protein-free plasma radioactivity at $15 \mathrm{~min}$, a value which increases slowly ( $\sim 2 \%$ at $30 \mathrm{~min})$. Considering that the protein-free plasma fraction of blood contains $\sim 29 \%$ 
of the total blood activity (Table 2), one can therefore estimate that free ${ }^{125}$ I represents $\sim 18 \%$ of the total circulating activity following in vivo injection of the tracer. Rather than indicating an increased deiodination of the tracer following in vivo injection, the apparently higher proportion of free ${ }^{125} \mathrm{I}$ following in vivo injection of ${ }^{125} \mathrm{I}-\mathrm{Ty}$-MCa ( 18\% of total blood activity) as compared with results from in vitro incubation of the tracer with mouse blood ( $4 \%$ of total blood activity) is likely due to the fact that unbound ${ }^{125} \mathrm{I}-\mathrm{Ty} \mathrm{r}-\mathrm{MCa}$ is available for organ distribution following in vivo injection in mice, whereas this is not the case following in vitro blood incubation of the tracer. These observations indicate that ${ }^{125} \mathrm{I}$-Tyr-MCa is probably accumulating in cells of various organs as expected for a cell penetrating peptide.

Table 2. In vivo blood distribution pattern and stability analysis of ${ }^{125} \mathrm{I}$-Tyr-MCa in protein-free plasma at 15 and 30 min following potassium perchlorate pretreatment and intravenous injection to mice.

\begin{tabular}{|c|c|c|c|c|}
\hline & Blood Distribution & & $15 \mathrm{~min}$ & $30 \mathrm{~min}$ \\
\hline \multirow[t]{5}{*}{${ }^{125}$ I-Tyr-MCa } & Blood cells & & 24 & 31 \\
\hline & Plasma proteins & & 47 & 42 \\
\hline & Protein-free plasma & & 29 & 27 \\
\hline & & Free ${ }^{125} \mathrm{I}$ & 62 & 72 \\
\hline & & ${ }^{125} \mathrm{I}-\mathrm{Ty}-\mathrm{MCa}$ & 38 & 28 \\
\hline
\end{tabular}

All of the results are expressed as \%.

\subsection{Biodistribution}

The biodistribution of ${ }^{125} \mathrm{I}-\mathrm{Tyr}-\mathrm{MCa}$ in $\mathrm{CD}-1$ mice at $60 \mathrm{~min}$ following tracer injection is shown in Figure 3. The tracer is mainly eliminated through the kidneys as shown by the high renal and urinary activities. High activities are also observed in the stomach, salivary gland, and thyroid, which correspond to ${ }^{125} \mathrm{I}$ uptake by these organs. ${ }^{125} \mathrm{I}$-Tyr-MCa does not cross the blood brain barrier, or at least badly, as shown by the extremely low brain and cerebellum activities. Figure 3 also compares the biodistributions of ${ }^{125} \mathrm{I}-\mathrm{Tyr}-\mathrm{MCa}$ with a pretreatment with the NaI symporter inhibitor, potassium perchlorate, to the condition without this pretreatment. As expected, the presence of potassium perchlorate significantly inhibits ${ }^{125}$ I uptake by the salivary glands and thyroid, which likely accounts for a significantly increased amount of blood circulating radioactivity. The biodistribution patterns are otherwise comparable between the two experiments.

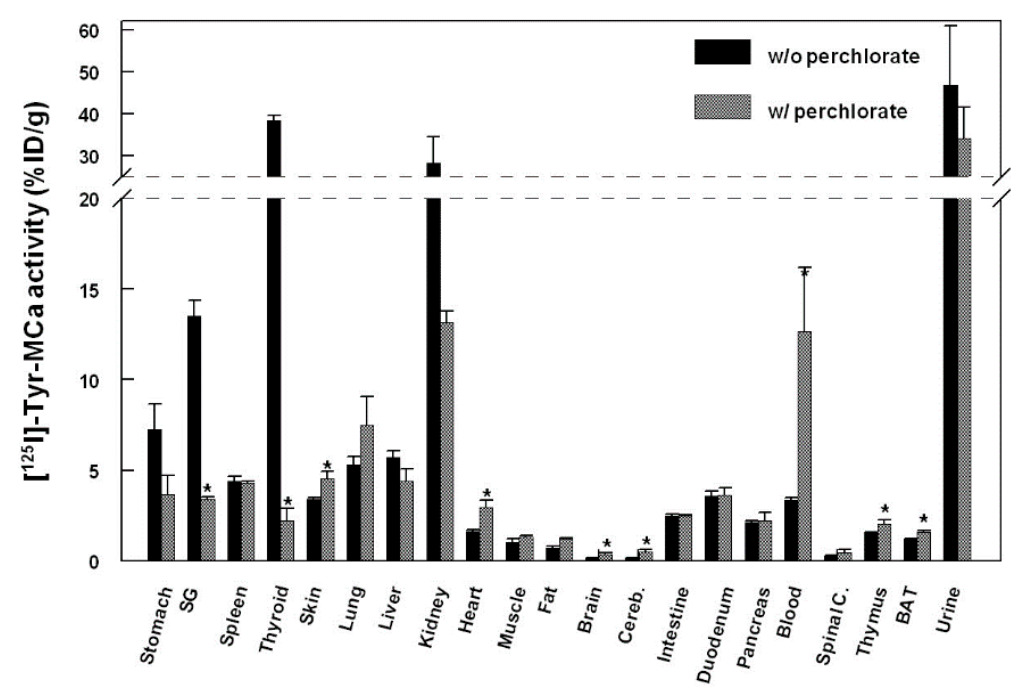

Figure 3. Biodistribution of ${ }^{125} \mathrm{I}-\mathrm{Ty}-\mathrm{MCa}$ in $\mathrm{CD}-1$ mice at $60 \mathrm{~min}$ post-injection and effect of the NaI symporter inhibitor potassium perchlorate. SG, salivary gland; Cereb., cerebellum; Spinal C., Spinal Cord, BAT, Brown Adipose Tissue. ${ }^{*} p \leqslant 0.05$. 


\subsection{In Vivo Imaging}

Presented in Figure 4 are representative images acquired in the same animal at $15 \mathrm{~min}$ (panel A), $30 \mathrm{~min}$ (panel B), and $60 \mathrm{~min}$ (panel C) following the intravenous injection of ${ }^{125} \mathrm{I}$-Tyr-MCa. The results from in vivo image quantification are presented in Figure 5. Non-invasive 60-min image quantification accurately reflects post-mortem organ biodistribution. As shown on images and as confirmed following image quantification, there is a progressive accumulation of ${ }^{125} \mathrm{I}$ in the thyroid, stomach, and salivary glands from 0 to $60 \mathrm{~min}$ post-injection. Renal elimination of the tracer begins immediately following injection and remains stable over time. Hepatic elimination of ${ }^{125} \mathrm{I}$-Tyr-MCa is lower than that occurring through the kidneys and is also stable over time.

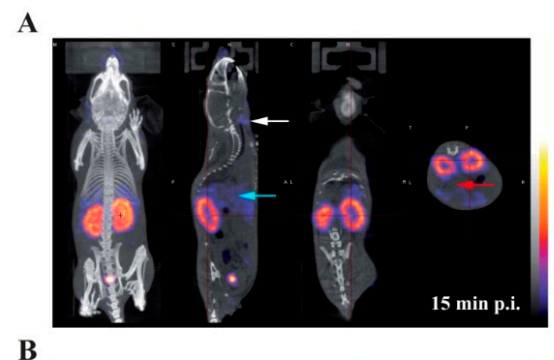

B

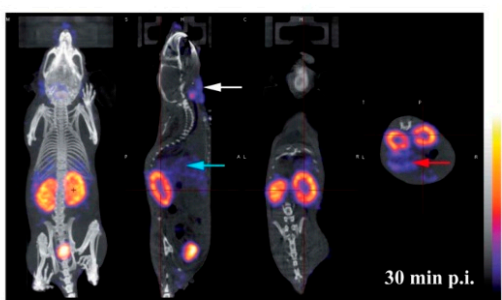

C

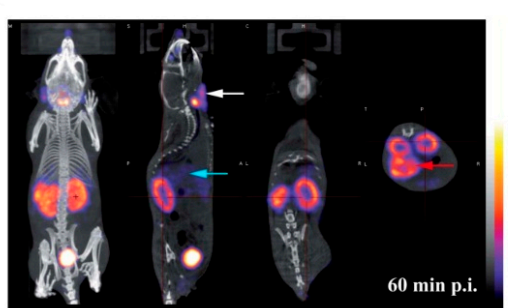

Figure 4. Whole-body SPECT/CT in vivo imaging of ${ }^{125} \mathrm{I}-\mathrm{Tyr}-\mathrm{MCa}$ in $\mathrm{CD}-1$ mice at $15 \mathrm{~min}$ post-injection (A); $30 \mathrm{~min}$ post-injection (B); and $60 \mathrm{~min}$ post-injection (C); from left to right, 3D rendering, sagittal, coronal, and transverse views of tracer activity. White, blue and red arrows are respectively pointing at salivary gland, liver, and stomach activity.

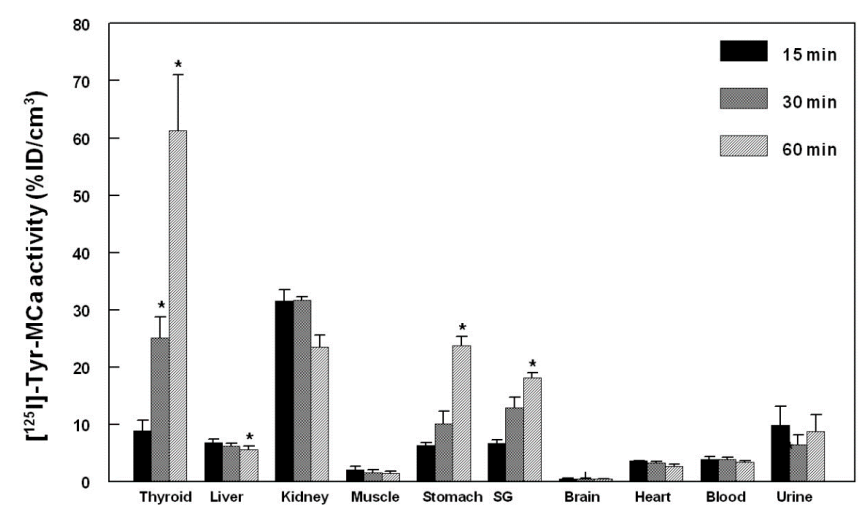

Figure 5. Quantification of in vivo tomographic images of ${ }^{125} \mathrm{I}-\mathrm{Tyr}-\mathrm{MCa}$ whole-body distribution at 15,30 , and 60 min post-injection. ${ }^{*} p \leqslant 0.05$ versus $15 \mathrm{~min}$. 


\section{Discussion}

MCa has potential as a cell penetrating peptide for drug delivery [11]. A better understanding of the in vivo behaviour of MCa following systemic delivery is therefore an important step in the development of the peptide. Accordingly, the present study reports the in vitro and in vivo stability as well as the in vivo biodistribution of radiolabeled MCa following intravenous injection in mice.

The role of the secondary structures on MCa stability and biodistribution was investigated by synthesizing Lin-Tyr-MCa containing no disulfide bridge and Tyr-MCa containing three disulfide bridges as encountered in the natural form of the toxin. The initial rationale for using Lin-Tyr-MCa lied in the lower technical difficulty related to the production of a peptide without multiple disulfide bonds. Both peptides were then successfully radioiodinated according to previously described [15] with excellent radiochemical stability over $24 \mathrm{~h}$. The in vitro stability of both radiolabeled peptides was then evaluated in mouse blood. Lin-Tyr-MCa was degraded as early as 15 min following initial contact with mouse blood leading to the appearance of two additional radiolabeled products demonstrating the instability of ${ }^{125} \mathrm{I}$-Lin-Tyr-MCa most likely due to the absence of disulfide bridges. Because of such degradation, the in vivo evaluations performed in the present study used the relatively natural form of Tyr-MCa that has shown an excellent stability in the presence of mouse blood in vitro.

The in vivo ${ }^{125} \mathrm{I}$-Tyr-MCa biodistribution experiments reported in the present study were performed at blood peptide concentrations in the range of $1 \mu \mathrm{M}$ which are therefore representative of the effective concentrations required for cell penetration and pharmacological action [5].

The present study led to several interesting conclusions. First, Tyr-MCa displayed blood stability in our experimental conditions. Apart from modest deiodination yielding free ${ }^{125} \mathrm{I}$ (see below), the peptide showed little degradation in agreement with the expected stability of disulfide-bridged toxins in vivo [16,17]. The three disulfide bridges that connect the six internal cysteine residues of MCa may confer a relatively high resistance to proteases. This finding further reinforces the competitiveness of MCa as a cell delivery vector. Second, the present study allowed important conclusions to be drawn regarding the fate of the peptide following intravenous injection. Both in vitro and in vivo data provide consistent conclusions. Up to $22 \%$ of ${ }^{125} \mathrm{I}$-Tyr-MCa was associated with blood cells, which is a first indication that ${ }^{125} \mathrm{I}-\mathrm{Ty}$ r-MCa has the ability to enter these cell types. The type of blood cell being preferentially targeted by ${ }^{125} \mathrm{I}$-Tyr-MCa remains to be determined, should MCa be used for targeted blood cell delivery. In addition, the observed values of thyroid activity were consistent with modest in vivo deiodination as previously demonstrated by Huang et al. [18]. Third, the data clearly demonstrated that ${ }^{125} \mathrm{I}$-Tyr-MCa did not reach neural tissues and that the peptide is therefore unlikely to cross the blood brain barrier. This observation will limit the number of applications where vector delivery to the brain is required, with the potential exception of pathological conditions such as brain tumors in which disruption of the blood brain barrier is expected to occur. A high activity was detected in the stomach, spleen, skin, lungs, intestine, duodenum, pancreas and liver. Non negligible labeling was observed in the heart, skeletal muscle, thymus and brown fat. In some organs such as salivary glands and the thyroid, the accumulation of radioactivity was linked to specific accumulation of free ${ }^{125}$ I which could readily be inhibited by potassium perchlorate treatment [19].

Fourth, the strong renal and urine accumulation of radioactivity implies that the main route of elimination of the peptide was renal. Kidney labeling did not change significantly between 15 and $60 \mathrm{~min}$, suggesting that rapid elimination occurred early following IV injection of the peptide. The only organs that demonstrated increased levels of radioactivity with time were those that accumulated free ${ }^{125} \mathrm{I}$ suggesting that ${ }^{125} \mathrm{I}-\mathrm{L}-\mathrm{MCa}$ distribution in vivo reached equilibrium rapidly following IV injection. 


\section{Materials and Methods}

\subsection{Materials}

Lactoperoxidase from bovine milk, hydrogen peroxide $30 \%(w / w)$ in $\mathrm{H}_{2} \mathrm{O}$ were supplied from Sigma-Aldrich (St. Louis, MO, USA); $\mathrm{Na}^{125} \mathrm{I}(3.7 \mathrm{GBq} / \mathrm{mL}$ ) from Perkin Elmer (Boston, BA, USA). Acetonitrile and trifluoroacetic acid were High Pressure Liquid Chromatography (HPLC) grade products and were purchased from Aldrich Chemical Co. (St, Louis, MO, USA). For radio-analyses: an HPLC apparatus (Shimadzu, Kyoto, Japan) equipped with $\mathrm{NaI}$ (Tl) scintillation detectors (LabLogic, Sheffield, UK) was used. Plasma and blood cell activities were assessed using a dose calibrator Capintec CRC-15R (Ramsey, NJ, USA). For in vitro stability centrifugate MiniSpin plus ${ }^{\circledR}$ (Eppendorf, Hamburg, Garmany) and a $10 \mathrm{~K}$ Omega ${ }^{\mathrm{TM}}$ membrane (Nanosep ${ }^{\circledR}$; Pall Life Science, East Hills, NY, USA) were used.

\subsection{Chemical Synthesis and Radiolabeling}

Chemical synthesis of Tyr-MCa and Lin-Tyr-MCa were performed as previously described [5,8]. Both MCa analogs were then radioiodinated according to Ahmadi et al. [15]. Briefly, $37 \mathrm{MBq}$ of ${ }^{125} \mathrm{I}$ were added to $10 \mu \mathrm{g}$ of each peptide in phosphate buffer $(50 \mathrm{mM}, \mathrm{pH}=7.4)$. The reaction was allowed to proceed for $30 \mathrm{~min}$ at room temperature (RT) after addition of $8 \mu \mathrm{L}(1 \mathrm{mg} / \mathrm{mL})$ lactoperoxidase and $10 \mu \mathrm{L} \mathrm{H}_{2} \mathrm{O}_{2}(1: 50,000)$.

Radioiodinated MCa analogues were then analysed by HPLC using a Vydac 218 TP C18 column, $\left(10 \mu \mathrm{m}, 4.6 \times 250 \mathrm{~mm}\right.$ ). The solvent system consisted of $\mathrm{H}_{2} \mathrm{O}-\mathrm{TFA} 0.1 \%$ (solvent $\mathrm{A}$ ) and acetonitrile $90 \%$-TFA $0.1 \%$ (solvent B). Tracer elution was achieved by applying a gradient of $0 \% \mathrm{~B}$ during $8.3 \mathrm{~min}$, 0\%-1\% B during $1.66 \mathrm{~min}, 1 \%-10 \%$ B during $1.66 \mathrm{~min}, 10 \%-60 \%$ B during $33.2 \mathrm{~min}, 60 \%-100 \%$ B during $1.66 \mathrm{~min}, 100 \% \mathrm{~B}$ during $8.3 \mathrm{~min}$ and $100 \%-0 \% \mathrm{~B}$ during $8.3 \mathrm{~min}$ (total run time, $65 \mathrm{~min}$ ) at a flow rate of $1 \mathrm{~mL} / \mathrm{min}$. The stability of the radiolabeling was determined by incubation of the radioiodinated complexes at RT for $24 \mathrm{~h}$, following which, an HPLC analysis was performed as described above.

\subsection{In Vitro Stability in Mouse Blood}

The in vitro stability of ${ }^{125} \mathrm{I}$-Tyr-MCa and ${ }^{125} \mathrm{I}$-Lin-Tyr-MCa were evaluated in mouse blood. The experiments were performed in triplicate. Twenty $\mathrm{MBq}(5 \mu \mathrm{g})$ of each radiolabeled $\mathrm{MCa}$ analogue were incubated for $180 \mathrm{~min}$ in $0.5 \mathrm{~mL}$ of mouse blood at $37{ }^{\circ} \mathrm{C}$, yielding a ${ }^{125} \mathrm{I}-\mathrm{Tyr}-\mathrm{MCa}$ and ${ }^{125} \mathrm{I}$-Lin-Tyr-MCa concentration of $2.3 \mu \mathrm{M}$. At different time point between $15 \mathrm{~min}$ and $180 \mathrm{~min}$, a $100 \mu \mathrm{L}$ blood sample was removed and then centrifuged $(2000 \times g, 5 \mathrm{~min})$ (pellet, fraction \#1). The separated plasma was filtered through a $10 \mathrm{~K}$ Omega ${ }^{\mathrm{TM}}$ membrane (Nanosep ${ }^{\circledR}$; Pall Life Science, East Hills, NY, USA) at $7000 \times g$ for 20 min (filter, fraction \#2; filtered solution, fraction \#3) followed by HPLC analyses using the above mentioned conditions. The blood samples were also used for the determination of the relative distribution of radioactivity in fractions $\# 1, \# 2$, and \#3 corresponding to blood cells, plasma proteins, and protein-free plasma, respectively. The potential presence of free ${ }^{125} \mathrm{I}$ in fractions \#1 and \#2 was analyzed by TLC using RP18 as stationary phase and physiological serum as mobile phase. In this analytical system, free iodine migrates to the solvent front and radioiodinated peptides remain at the deposit point.

\subsection{In Vivo Experimental Protocol}

\subsubsection{Animals}

Eight standard CD-1 mice were purchased from Charles River Laboratories (L'Arbresle, France) and housed for 1 week prior to inclusion in the experimental protocol. Conscious animals were restrained for tracer injection in a tail vein. All experimental procedures were performed in accordance with the European Ethics Committee on Animal Care Guidelines (Directive 
86/609/EEC) and were approved by the local Animal Care and Use Committee of the University (ComEth Grenoble, C2EA n 12,2012).

\subsubsection{In Vivo ${ }^{125} \mathrm{I}-\mathrm{MCa}$ Stability}

Two animals were dedicated to the evaluation of ${ }^{125} \mathrm{I}-\mathrm{Tyr}-\mathrm{MCa}$ in vivo stability. The animals were pretreated by the $\mathrm{NaI}$ symporter inhibitor potassium perchlorate and then injected with $55 \mathrm{MBq}$ $(15 \mu \mathrm{g})$ of tracer $(2.3 \mu \mathrm{M}$ final in vivo concentration considering a total blood volume of $1.5 \mathrm{~mL}$. At 15 and $30 \mathrm{~min}(n=1)$ following injection, the animals were anesthetized using pentobarbital $(60 \mathrm{mg} / \mathrm{kg}$, $\mathrm{IP})$ and a transmural puncture was performed in order to withdraw a blood sample directly from the left ventricular cavity. The blood sample was immediately centrifuged, the plasma was filtered, and the filtered solutions were analyzed by HPLC as described above. In addition, the distribution of radioactivity in fractions obtained as described above was also performed.

\subsubsection{Biodistribution}

${ }^{125} \mathrm{I}$-Tyr-MCa $(1.5 \pm 0.0 \mathrm{MBq} / \mathrm{g}$ body weight; $\sim 35 \mathrm{MBq}$ total $(10 \mu \mathrm{g}$, final in vivo concentration $1.5 \mu \mathrm{M}$ considering a total blood volume of $\sim 1.5 \mathrm{~mL}$ ) was injected in one of the tail vein (IV) of 6 conscious and restrained animals (body weight, $23.7 \pm 0.3 \mathrm{~g})$ in the absence $(n=3)$ or presence $(n=3)$ of the NaI symporter inhibitor potassium perchlorate $(3 \mathrm{mg} / \mathrm{kg}$ administered IV $\sim 15 \mathrm{~min}$ prior to ${ }^{125} \mathrm{I}$-Tyr-MCa injection). Three out of 6 animals were anesthetized using isoflurane $1.5 \%$ (Aerrane, Baxter, France) in a 1:1 mixture of room air and oxygen, and then placed in a temperature-controlled bed for whole-body SPECT/CT acquisitions. SPECT/CT experiments were performed using a four-head gamma camera dedicated to small animals (NanoSPECT/CT, Bioscan/Mediso) equiped with 9-pinholes collimators of 1.4 diameter. The scans were acquired sequentially using Nucline software (Mediso, Budapest, Hungary) at 15, 30, and 60 min post-tracer injection. The SPECT parameters were: 24 projections and $20 \mathrm{sec}$ per projection. The $\mathrm{CT}$ was performed between the 30 and 60 min nuclear image acquisition at $45 \mathrm{keV}$. Reconstruction of scans was carried out using HiSPECT NG (Bioscan, Goettingen, Germany). CT and SPECT acquisitions were reconstructed, fused and quantified using dedicated software (InVivo Scope, Bioscan). SPECT scale, obtained in $\mathrm{kBq} /$ voxel, was converted into percentage of injected dose per $\mathrm{cm}^{3}\left(\% \mathrm{ID} / \mathrm{cm}^{3}\right)$ and set to similar levels to allow direct visual comparison. Regions of interest (ROIs) were drawn on the thyroid, liver, kidney, skeletal muscle, stomach, salivary gland, brain, heart, myocardial left ventricle (for blood activity determination) and bladder.

\subsubsection{Post Mortem Analysis}

Sixty min following tracer injection, all 6 anesthetized animals were euthanized by cervical dislocation and samples from the heart, lung, liver, spleen, kidney, stomach, intestine, duodenum, pancreas, salivary glands, thyroid, skin, skeletal muscle, pancreas, thymus, brain, fat, brown fat, spinal cord, blood, and urine were obtained. Radioactivity in organ and blood samples was measured thanks to a gamma-well counter (Cobra II, Packard Instruments, Courtaboeuf, France) with a 15-75 keV energy window for ${ }^{125} \mathrm{I}$. All tissue counts were corrected for background. Results were expressed as percentage of the injected dose per gram of wet weight (\% ID $/ \mathrm{g})$.

\subsection{Data Analysis}

Data were given as mean \pm SEM and compared using Student $t$-test and Kruskall-Wallis non parametric test (Systat software, San Jose, CA, USA) with a level of significance of 0.05 .

\section{Conclusions}

In summary, the results from the present study indicated that $\mathrm{MCa}$ is a stable peptide vector in vivo, that it targets peripheral organs mainly with interesting quantitative differences, that blood 
cells also appear to accumulate the peptide and that the main route of elimination occurs through the kidneys. This study will therefore delineate the field of applications in which MCa could be used to deliver cargo into cells in vivo.

Acknowledgments: This work was partly funded by the French program "Investissements d'Avenir run by the "Agence Nationale pour la Recherche"; grant "Infrastructure d'avenir en Biologie et Santé-ANR-11-INBS-0006". MDW is supported by a LabEx ANR grant N ANR-11-LABX-0015.

Author Contributions: Pascale Perret, Laurent Riou, Mitra Ahmadi, and Sandrine Bacot wrote the paper. Michel De Waard, Catherine Ghezzi, Pascale Perret and Laurent Riou conceived and designed the experiments. Pascale Perret, Mitra Ahmadi, Alexis Broisat, Julien Pecher, Cathy Poillot, Sandrine Bacot performed the experiments and acquired data. Laurent Riou, Pascale Perret, Mitra Ahmadi and Sandrine Bacot analyzed and interpreted the data. All the authors critically revised and approved the final version of the manuscript.

Conflicts of Interest: The authors declare no conflict of interest.

\section{References}

1. Mosbah, A.; Kharrat, R.; Fajloun, Z.; Renisio, J.G.; Blanc, E.; Sabatier, J.M.; El Ayeb, M.; Darbon, H. A new fold in the scorpion toxin family, associated with an activity on a ryanodine-sensitive calcium channel. Proteins 2000, 40, 436-442. [CrossRef]

2. Estève, E.; Mabrouk, K.; Dupuis, A.; Smida-Rezgui, S.; Altafaj, X.; Grunwald, D.; Platel, J.-C.; Andreotti, N.; Marty, I.; Sabatier, J.-M.; et al. Transduction of the scorpion toxin maurocalcine into cells. Evidence that the toxin crosses the plasma membrane. J. Biol. Chem. 2005, 280, 12833-12839. [CrossRef] [PubMed]

3. Ram, N.; Aroui, S.; Jaumain, E.; Bichraoui, H.; Mabrouk, K.; Ronjat, M.; Lortat-Jacob, H.; de Waard, M. Direct peptide interaction with surface glycosaminoglycans contributes to the cell penetration of maurocalcine. J. Biol. Chem. 2008, 283, 24274-24284. [CrossRef] [PubMed]

4. Aroui, S.; Ram, N.; Appaix, F.; Ronjat, M.; Kenani, A.; Pirollet, F.; de Waard, M. Maurocalcine as a non toxic drug carrier overcomes doxorubicin resistance in the cancer cell line MDA-MB 231. Pharm. Res. 2009, 26, 836-845. [CrossRef] [PubMed]

5. Boisseau, S.; Mabrouk, K.; Ram, N.; Garmy, N.; Collin, V.; Tadmouri, A.; Mikati, M.; Sabatier, J.-M.; Ronjat, M.; Fantini, J.; et al. Cell penetration properties of maurocalcine, a natural venom peptide active on the intracellular ryanodine receptor. Biochim. Biophys. Acta 2006, 1758, 308-319. [CrossRef] [PubMed]

6. Jayagopal, A.; Su, Y.R.; Blakemore, J.L.; Linton, M.F.; Fazio, S.; Haselton, F.R. Quantum dot mediated imaging of atherosclerosis. Nanotechnology 2009, 20, 165102. [CrossRef] [PubMed]

7. Poillot, C.; Dridi, K.; Bichraoui, H.; Pêcher, J.; Alphonse, S.; Douzi, B.; Ronjat, M.; Darbon, H.; de Waard, M. D-Maurocalcine, a pharmacologically inert efficient cell-penetrating peptide analogue. J. Biol. Chem. 2010, 285, 34168-34180. [CrossRef] [PubMed]

8. Ram, N.; Weiss, N.; Texier-Nogues, I.; Aroui, S.; Andreotti, N.; Pirollet, F.; Ronjat, M.; Sabatier, J.-M.; Darbon, H.; Jacquemond, V.; et al. Design of a disulfide-less, pharmacologically inert, and chemically competent analog of maurocalcine for the efficient transport of impermeant compounds into cells. J. Biol. Chem. 2008, 283, 27048-27056. [CrossRef] [PubMed]

9. Aroui, S.; Brahim, S.; de Waard, M.; Bréard, J.; Kenani, A. Efficient induction of apoptosis by doxorubicin coupled to cell-penetrating peptides compared to unconjugated doxorubicin in the human breast cancer cell line MDA-MB 231. Cancer Lett. 2009, 285, 28-38. [CrossRef] [PubMed]

10. Aroui, S.; Brahim, S.; Hamelin, J.; de Waard, M.; Bréard, J.; Kenani, A. Conjugation of doxorubicin to cell penetrating peptides sensitizes human breast MDA-MB 231 cancer cells to endogenous TRAIL-induced apoptosis. Apoptosis Int. J. Program. Cell Death 2009, 14, 1352-1365. [CrossRef] [PubMed]

11. Aroui, S.; Brahim, S.; Waard, M.D.; Kenani, A. Cytotoxicity, intracellular distribution and uptake of doxorubicin and doxorubicin coupled to cell-penetrating peptides in different cell lines: A comparative study. Biochem. Biophys. Res. Commun. 2010, 391, 419-425. [CrossRef] [PubMed]

12. Aroui, S.; Mili, D.; Brahim, S.; de Waard, M.; Kenani, A. Doxorubicin coupled to penetratin promotes apoptosis in $\mathrm{CHO}$ cells by a mechanism involving c-Jun NH2-terminal kinase. Biochem. Biophys. Res. Commun. 2010, 396, 908-914. [CrossRef] [PubMed] 
13. Tisseyre, C.; Ahmadi, M.; Bacot, S.; Dardevet, L.; Perret, P.; Ronjat, M.; Fagret, D.; Usson, Y.; Ghezzi, C.; de Waard, M. Quantitative evaluation of the cell penetrating properties of an iodinated Tyr-L-maurocalcine analog. Biochim. Biophys. Acta 2014, 1843, 2356-2364. [CrossRef] [PubMed]

14. Mabrouk, K.; Ram, N.; Boisseau, S.; Strappazzon, F.; Rehaim, A.; Sadoul, R.; Darbon, H.; Ronjat, M.; de Waard, M. Critical amino acid residues of maurocalcine involved in pharmacology, lipid interaction and cell penetration. Biochim. Biophys. Acta 2007, 1768, 2528-2540. [CrossRef] [PubMed]

15. Ahmadi, M.; Bacot, S.; Poillot, C.; Desruet, M.-D.; Perret, P.; Riou, L.; Cestèle, S.; Couvet, M.; Bourgoin, S.; Sève, M.; et al. Selective mono-radioiodination and characterization of a cell-penetrating peptide: L-Tyr-Maurocalcine. Radiochim. Acta 2014, 102, 1047-1057. [CrossRef]

16. Maiti, N.R.; Surewicz, W.K. The role of disulfide bridge in the folding and stability of the recombinant human prion protein. J. Biol. Chem. 2001, 276, 2427-2431. [CrossRef] [PubMed]

17. Melnik, B.S.; Povarnitsyna, T.V.; Glukhov, A.S.; Melnik, T.N.; Uversky, V.N.; Sarma, R.H. SS-Stabilizing proteins rationally: Intrinsic disorder-based design of stabilizing disulphide bridges in GFP. J. Biomol. Struct. Dyn. 2012, 29, 815-824. [CrossRef] [PubMed]

18. Huang, C.C.; Friedman, A.M.; Rayudu, G.V.; Clark, P.; Fordham, E.W. In vivo stability and distribution of [131I]iodomethyl trimethylammonium chloride: Concise communication. J. Nucl. Med. Off. Publ. Soc. Nucl. Med. 1980, 21, 679-681.

19. Yu, K.O.; Narayanan, L.; Mattie, D.R.; Godfrey, R.J.; Todd, P.N.; Sterner, T.R.; Mahle, D.A.; Lumpkin, M.H.; Fisher, J.W. The pharmacokinetics of perchlorate and its effect on the hypothalamus-pituitary-thyroid axis in the male rat. Toxicol. Appl. Pharmacol. 2002, 182, 148-159. [CrossRef] [PubMed]

(C) 2015 by the authors; licensee MDPI, Basel, Switzerland. This article is an open access article distributed under the terms and conditions of the Creative Commons by Attribution (CC-BY) license (http:/ / creativecommons.org/licenses/by/4.0/). 